\title{
Myelin Oligodendrocyte Glycoprotein Antibody Associated Transverse Myelitis
}

\author{
Iveta Chroustová2, Miroslav Mareš², Leoš Ungermann ${ }^{1,3}$, Edvard Ehler ${ }^{1,2, *}$
}

\section{ABSTRACT}

Antibodies against myelin oligodendrocyte glycoprotein cause inflammatory lesions of central myelin - in optic nerves, of the brainstem, and spinal cord. There are characteristic changes of CNS white matter, protein-cytological association in cerebrospinal fluid, MOG IgG antibodies, a very important differential diagnosis and a relatively mild course.

\section{KEYWORDS}

myelin oligodendrocyte glycoprotein; inflammation; spinal cord; antibodies

\section{AUTHOR AFFILIATIONS}

${ }^{1}$ Faculty of Health Care Studies, Pardubice University, Czech Republic

${ }^{2}$ Department of Neurology, Pardubice Regional Hospital, Czech Republic

${ }^{3}$ Department of Radiology, Pardubice Regional Hospital, Czech Republic

* Corresponding author: Department of Neurology, Faculty of Health Care Studies, Pardubice University and Pardubice Regional Hospital, Czech Republic; e-mail: edvard.ehler@nempk.cz

Received: 16 May 2019

Accepted: 16 August 2019

Published online: 30 October 2019

Acta Medica (Hradec Králové) 2019; 62(3): 123-126

https://doi.org/10.14712/18059694.2019.136

(C) 2019 The Authors. This is an open-access article distributed under the terms of the Creative Commons Attribution License (http://creativecommons.org/licenses/by/4.0), which permits unrestricted use, distribution, and reproduction in any medium, provided the original author and source are credited. 


\section{INTRODUCTION}

Myelin oligodendrocyte glycoprotein (MOG) is a component of myelin sheaths that is solely expressed in the central nervous system and thought to be an important target of inflammatory demyelinating disorders. The clinical features of MOG antibody-associated demyelination different onset phenotypes are important for prognosis of the disease (1). MOG-IgG-seropositive patients can be divided into four groups: MOG-ON (optic neuritis), MOGTM (transverse myelitis), MOG-pure brain symptoms and MOG-ON+TM (2).

Because we have diagnosed a young man with transverse myelitis and a high titer of MOG-IgG antibody we have decided to publish this relatively new clinical disorder.

\section{CASE REPORT}

A 33-year old up till now healthy clerk was referred to neurology from urology. A month earlier, the retention of

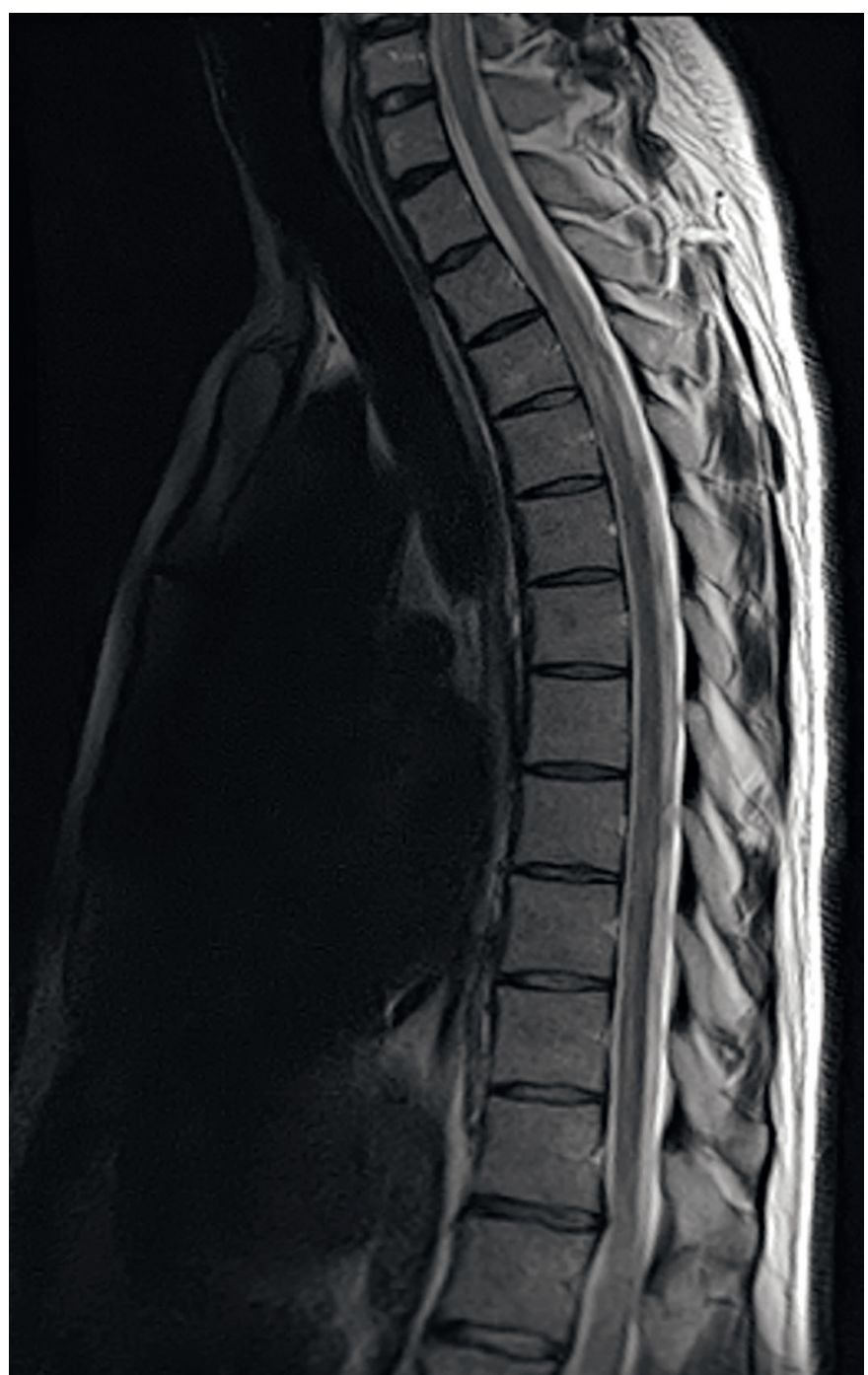

Fig. 1 Sagittal T2 weighted MRI image of the thoracic spine intramedullary hyperintense lesion: clearly seen at the Th3-5 level, marginally viewed at the distal part of lumbar spinal cord. urine began to occur. After catheterization, 1.5 liter urine was let out. He also complained of a progressive burning of the feet, followed by ascendent hypesthesia of the leg and trunk up to above xiphoid (Th6). During the neurological examination done at admission, spinal cord symptomatology with hypesthesia up to Th6 level, mild spastic paraparesis and a spastic sphincter were established. The patient was able to walk, but slowly, without any support.

On the MR of the brain and spinal cord with gadolinium, a couple of focal spinal cord changes in cervical and thoracic level were found. One focal myelopathy was three spinal cord segments long (Fig. 1, 2, 3, 4). There were no clear focal changes in the white matter of the brainstem or brain. In the cerebrospinal fluid we found hyperproteinorhachia (2.5 g/liter; 0,2-0,4), decreased lactate $(0.90 \mathrm{mmol} / \mathrm{l} ; 1,20-2,10)$ and glucose $(2.85 \mathrm{mmol} / \mathrm{l}$; $2,50-4,50)$ and normal chlorides (120 mmol/1; 120-130). Pleocytosis was found with 349 cells and a prevalence of mononuclears-336 and polymorphonuclears -13 .

At this point we consulted a specialist in infectious diseases who expressed suspicion of infectious disease and recommended intravenous therapy with ceftriaxone and herpesin. Once administered, the therapies recommended by the ID specialist did not result in an improved neurological condition of the patient.

We sent the cerebrospinal fluid to the reference laboratory (Topelex), but there was only a very small intrathecal production of immunoglobulins and no infectious agents were found (borreliosis, HSV 1 and 2, VZV, CMV, tick meningoencephalitis, neurolues, chlamydia, mycoplasma, entoriviri, listeria monocytogenes, L. interrogans; including HIV in blood). MRZ reaction was not performed.

Because of prominent and long intraspinal focuses, we suspected an inflammatory origin, we thought it could

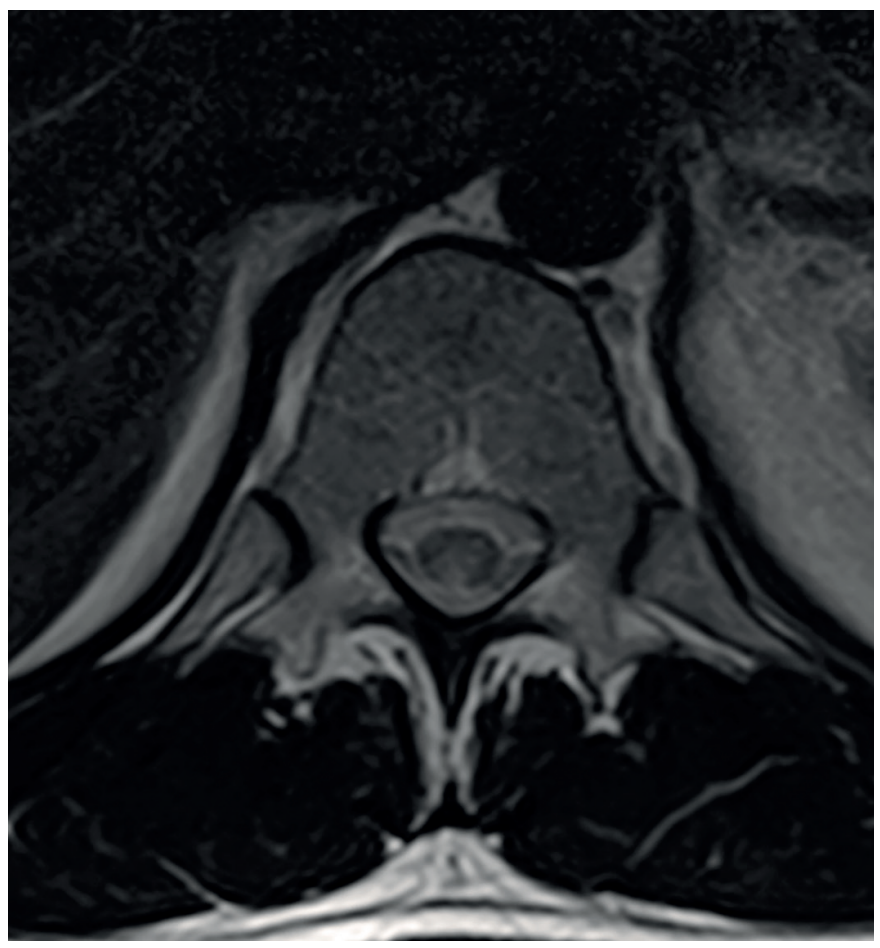

Fig. 2 Axial T2 weighted MRI image of the thoracic spine intramedullary hyperintense lesion at the dorsal part of spinal cord. 


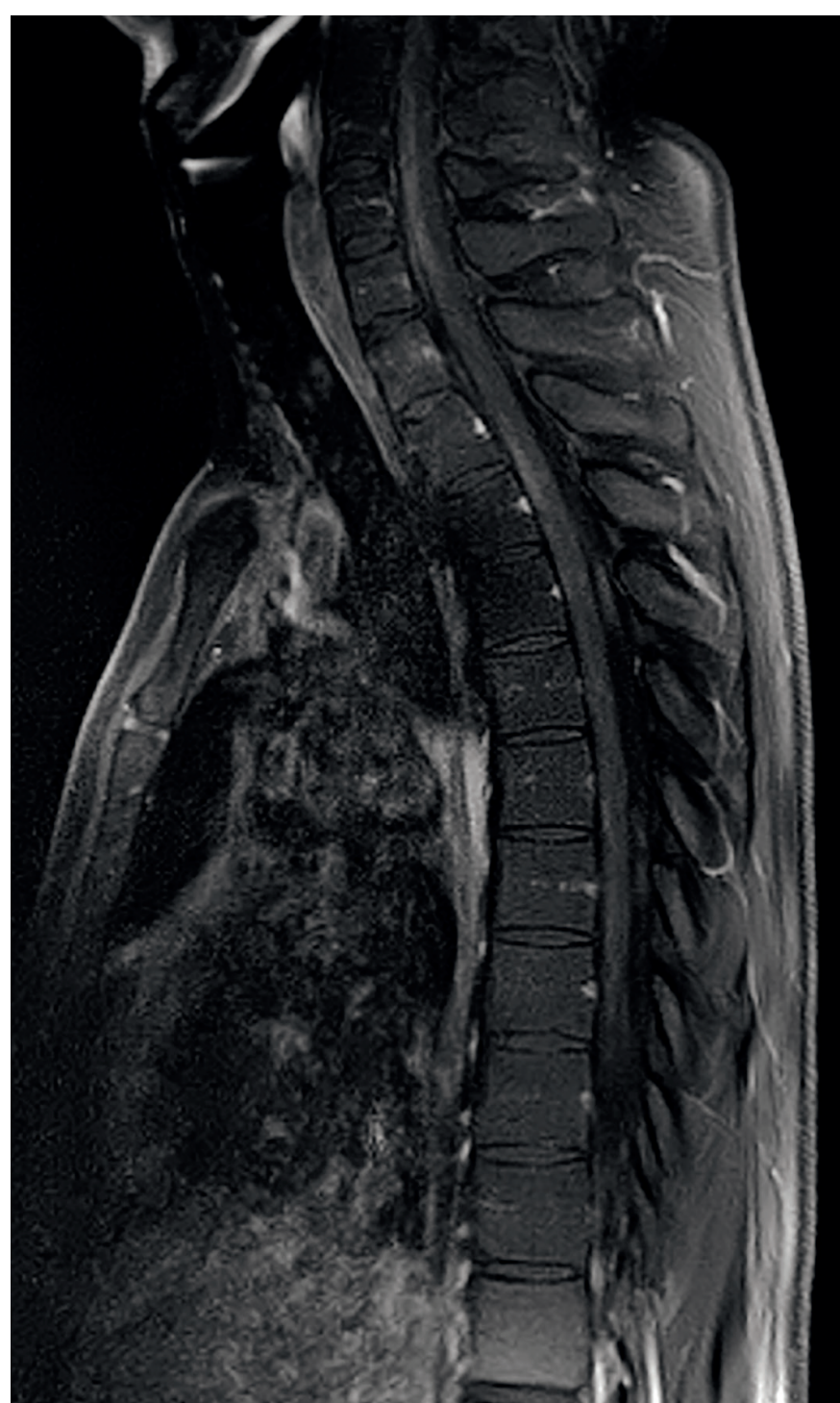

Fig. 3 Axial T1 weighted MRI image of the thoracic spine after gadolinium administration - inhomogeneous nodular opacification of the lesions same as picture No. 1.

be an atypical finding of multiple sclerosis - but no oligoclonal bands were found. As a second option we thought of neuromyelitis optica spectrum disorder - but no changes of the optic nerves (MRI, VEP, OCT) or aquaporin-4 antibodies were found. Because of suspected sarcoidosis we treated the patient with methylprednisolone $5 \mathrm{~g}$ intravenously. After $2 \mathrm{~g}$ of methylprednisolone the urologic complaints, hypesthesia and also spastic paraparesis began to improve while sarcoidosis was excluded.

We have excluded sarcoidosis and, according to MRI spinal cord changes with negativity of aquaporin-4-antibodies, we indicated anti-MOG antibodies (myelin oligodendrocyte glycoprotein) and it was positive in serum. The positivity anti-MOG antibodies was established in a specialized reference laboratory Topelex. The cell-based assay is used and with help of fluoresence is evaluated either on native cell culture and also on transfected cells. There is only qualitative evaluation - antibody titer higher than $1: 10$ is expressed as positive.

At the admission of this patient we supposed that it could be an infections diseased of bacterial or viral origin.

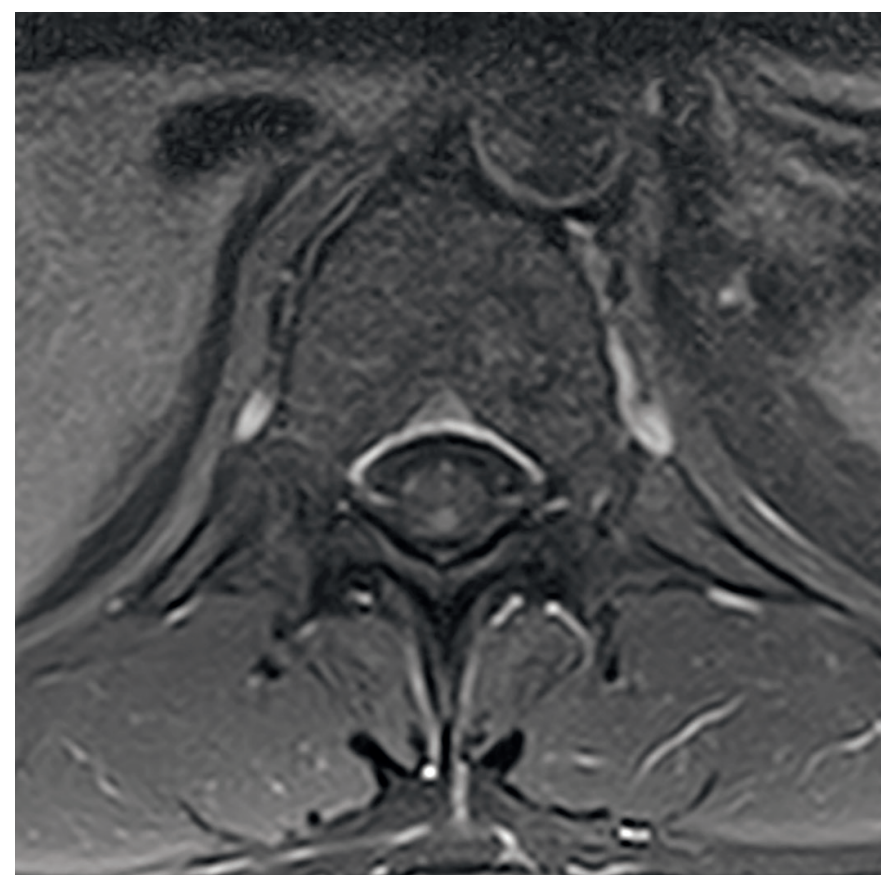

Fig. 4 Axial T1 weighted MRI image of the lumbar spine after gadolinium administration - inhomogeneous nodular opacification of the lesions.

Our suspicion increased with the proteino-cytological association in cerebrospinal fluid and also a prominent positivity of a chemokine CXCL13, that is usually found in borreliosis. But the patient did not improve after combination (cetriaxone and herpesine) therapy and tests for the most common neuroinfections were not positive. We concluded, that the patient has transverse myelitis with anti-MOG antibodies, a new clinical disorder. At discharge he had improved, with mild spastic paraparesis, hypesthesia only of the low extremities and minimal dysuria. At the time, he was being treated with a small dose of medrol $(8 \mathrm{mg} / \mathrm{d})$. He will be monitored and treated in the multiple sclerosis centre.

\section{DISCUSSION}

Over the past few years, new generation cell-based assays have demonstrated a robust association of autoantibodies to human MOG with optic neuritis, myelitis and brainstem encephalitis (3). Disorders based on anti-MOG demyelination are immunopathogenetically distinct from both classic multiple sclerosis and aquaporin-4-IgG positive neuromyelitis optica spectrum disorder (NMOSD) (4). Based on evidence from immunopathological studies suggesting a direct pathogenic impact of MOG-IgG, neuropathological studies demonstrating discrete histopathological features, serological studies reporting a lack of aquaporin-4-IgG in almost all MOG-IgG-positive patients, and cohort studies suggesting differences in clinical and paraclinical presentation, treatment response and prognosis, MOG-IgG is now considered to denote a disease entity in its own right (1).

In patients with transverse myelitis there is a number of various diseases that should be taken into account 
(Table 1). Second to clinical findings, MRI imaging is the most important examination (5). Also cerebrospinal fluid examination, tests for infectious diseases, and an assessment of auto-antibodies are unavoidable in order to achieve a correct diagnosis (6). In our 33-year old, active man, the first suspicion was of an infectious disease. According to a consulted Infectious Disease Specialist, neuroborreliosis. Yet, this was not confirmed. Multiple sclerosis was the second diagnosis - but oligoclonal bands were not found. Extensive transverse myelitis may be part of neuromyelitis optica. An MRI of the optic nerves, visual evoked potentials, and optic coherence tomography resulted in normal findings. Antibodies against aquaporin 4 were not found. According to the spinal cord MRI, we also suspected spinal sarcoidosis, which was later not confirmed. Finally, antibodies against MOG in cerebrospinal fluid were found and we could achieve the correct diagnosis - MOG-IgG transverse myelitis.

Tab. 1 Causes of transverse myelitis.

\begin{tabular}{|l|l|}
\hline $\begin{array}{l}\text { Demyelinating } \\
\text { disorders }\end{array}$ & $\begin{array}{l}\text { Multiple sclerosis } \\
\text { Neuromyelitis optica spectrum disorders } \\
\text { Acute disseminated encephalomyelitis } \\
\text { (ADEM) } \\
\text { Adrenoleukodystrophy }\end{array}$ \\
\hline $\begin{array}{l}\text { Non-infectious } \\
\text { inflammatory } \\
\text { disorders }\end{array}$ & $\begin{array}{l}\text { Post-infectious transverse myelitis } \\
\text { Primary vasculitis of CNS } \\
\text { Lupus erythematodes } \\
\text { Paraneoplastic myelopathies (breast, lung, } \\
\text { lymphoma) } \\
\text { Sjögren syndroma }\end{array}$ \\
\hline $\begin{array}{l}\text { Vascular } \\
\text { disorders }\end{array}$ & $\begin{array}{l}\text { Spinal cord infarctions } \\
\text { Spinal dural arteriovenous malformations }\end{array}$ \\
\hline $\begin{array}{l}\text { Infectious } \\
\text { disorders }\end{array}$ & $\begin{array}{l}\text { Viral (herpes, CMV, West Nile virus, HIV) } \\
\text { Bacterial (staphylococcus, streptococcus, } \\
\text { borrelia, mycobacterium) } \\
\text { Parasitary (schistosomiasis) }\end{array}$ \\
\hline
\end{tabular}

Patients with anti-MOG transverse myelitis are young - 24 years at onset (2), have higher titer of anti
MOG IgG than patients with anti-MOG optic neuritis, and have increased cerebrospinal fluid leukocytes. Though patients with anti-MOG-TM tend to relapse more frequently, the outcome is favorable - with only $2 \%$ becoming wheelchair-dependent. Intravenous methylprednisolone during acute attacks have proven to be the most successful therapy. Only a small number of patients were treated with intravenous immunoglobulin or plasma exchange, which resulted in only a weak effect. Only children were treated with rituximab or azathioprine in the first line. For chronic maintenance therapy corticosteroids with azathioprine or mycophenolate mofetil were used. In our 33-year old patient we succeeded with intravenous methylprednisolone and then with decreasing doses of medrol.

\section{CONCLUSION}

Anti-MOG transverse myelitis is a newly established disease. The differential diagnosis is especially against neuromyelitis optica and multiple sclerosis. Though the disease tends to relapse, the outcome is favorable in most patients.

\section{REFERENCES}

1. Jarius S, Paul F, Aktas O, et al. MOG Encephalomyelitis: International Recommendations on Diagnosis and Antibody Testing. Journal of Neuroinflammation 2018; 15: 134-44.

2. Zhou Y, Jia X, Yang H,et al. Myelin Oligodendrocyte Glycoprotein Antibody-Associated Demyelination: Comparison Between Onset Phenotypes 2018; 26: 175-83

3. Yeh EA, Nakashima I. Live-cell Based Assays Are the Gold Standard for Anti-MOG-Ab Testing. Neurology 2019; 92: 501-2.

4. Han J, Yang M, Zhu J, Jin T. Complexity and Wide Range of Neuromyelitis Optica Spectrum disorders: more than typical manifestations. Neuropsychiatric Disease and Treatment 2017; 13: 2653-60.

5. Jurynchyk M, Messin S, Woodhall MR,et al. Clinical Presentation and Prognosis in MOG-antibody Disease: a UK Study. Brain 2017; 140: 3128-38.

6. Cobo-Calvo A, Ruiz A, Maillart E, et al. Clinical Spectrum and Prognostic Value of CNS MOG Autoimmunity in Adults. The MOGADOR study. Neurology 2018; 90: e1858-e1869. 